\title{
Interactive comment on "Effects of extraction conditions on the redox properties of soil organic matter (SOM) and its ability to stimulate microbial iron(III) mineral reduction by electron shuttling" by Yuge Bai et al.
}

\section{Anonymous Referee \#1}

Received and published: 2 December 2019

Bai et al. compare redox properties of a water extract with humic and fulvic acid extracts of a soil. Additionally, fulvic acids and humic acids were extracted of the water extract. All extractions were performed under air as well as under N2.

The final conclusion is that (oxic or anoxic) alkaline extracts are not suitable to substitute natural organic matter in redox-experiments. is still popular in current papers and textbooks, sometimes even described as the 
method of choice. The topic is therefore both important and in time. Also, I appreciate such a clear statement from groups which frequently used humic acids in the past. The paper is well written and nicely illustrated by figures and tables.

One general comment: In the manuscript the abbreviation "SOM" is used to address the water extractable fraction (tables, figures, text). This seems misleading to me: SOM comprises all non-living soil organic matter, while a water extract is done to gain something similar to the dissolved organic matter or the fraction which can be dissolved or mobilized (colloidal fraction) during rain events or rising groundwater. I think, a better name for the water extract would be "water extract (WE)" or "water extractable organic matter (WEOM)" instead of SOM. WE or WEOM also shows that one is aware of the difference between a water extract and the real DOM of a soil solution.

To my knowledge, humic substances are meant to extract all HA and FA of a sample, while it is accepted that a large fraction may remain behind. I therefore wonder if it is meaningful to compare extracted $\mathrm{C}$ amounts from alkaline extraction with water extraction. With respect to the different extraction of functional groups or artefacts during exposure to $\mathrm{pH} 12$, the comparison between WEOM and FA/HA of WEOM are certainly more robust. (For example, does the sum of EAC(FA of WEOM, oxic) and EAC (HA of WEOM oxic) equals EAC(WEOM) or do we see artefacts? The sum of FA of WEOM+HA of WEOM $(0.035 \mathrm{~g} \mathrm{C})$ is very close to the total WEOM $(0.036 \mathrm{~g} \mathrm{C})$ ).

Other comments:

First sentence: I propose to delete "including humic substances". The main point can be made without and if alkaline extraction causes that many artefacts, it may even be wrong.

Line 15: name soil, sampled depth/horizon and $\mathrm{pH}$ of the soil.

Printer-friendly version

Line 18/19: “. . 100 times more. ..” see general comment above.

Discussion paper

Line 25: ...changes in functional groups ... is there space to name observed or as-

(1) 
sumed changes in the abstract?

Line 27: Delete "at neutral $\mathrm{pH}$ ". Rainwater has a $\mathrm{pH}$ of 5 , soil solutions are rather variable in $\mathrm{pH}$. The choice of $\mathrm{pH}$ should therefore be adopted to the soil and the specific research question. Ionic strength and ionic composition will also play a role. Was $\mathrm{pH} 7$ a good choice for the Cambisol?

Line 81: Was the mineral topsoil horizon sampled or the mineral topsoil plus litter layer? Do the upper $15 \mathrm{~cm}$ include material of the B horizon? Is anything known about the $\mathrm{Fe}$ oxide content of the soil? If yes, does the amount of Fe oxides fit to the observed Fe concentration in the extracts?

Line 63: please give ferrihydrite concentration in $\mathrm{mM} \mathrm{Fh-Fe} \mathrm{or} \mathrm{in} \mathrm{weight} \mathrm{\% .} \mathrm{As} \mathrm{the}$ composition of ferrihydrite is still under debate and as a mineral structure can be given in different ways, $\mathrm{mM} F \mathrm{~F}$ is not unambiguous.

Line 194: delete the "e"

Line 211: please correct, the table in Fig.2 give $44 \mu \mathrm{mol}$ e- mmolC-1, instead of 45.

Line 304-307: sentence?

Line 400: "adsorption" instead of "absorption"

Table 1 is unclear. What was analyzed, DOC (after 0.45 filtration) or TOC? Why are concentrations and masses of $C$ needed? Can the descriptive first and second rows of the table be optimized? "Water extracted" above columns 4,5,8, and 9 is misleading, as the treatment is a chemical extraction of a water extract. The latter also applies for the figures. Replace SOM by WE or WEOM or the like.

Figure 3 is very confusing due to the complex legend.

Printer-friendly version

Figure 1, although nice, could be sacrificed to show NMR or EEMS data. It's a pity, that these ended up in the SI. Can NMR spectra be given at least in the SI?

Discussion paper 
Title: While the manuscript is concise and clear, the title is less straight. How about having the main message in the title?

Interactive comment on Biogeosciences Discuss., https://doi.org/10.5194/bg-2019-308, 2019. 